\title{
Class, Cultural Capital, and the Mobile Phone
}

\author{
BREDA LUTHAR and SAMO KROPIVNIK* \\ University of Ljubljana
}

\begin{abstract}
This article uses data from a representative survey on the applications of information and communication technologies to investigate the use of the mobile phone as a cultural object by different groups of respondents/consumers. Setting out from the premise that the symbolic and artefactual nature of new media, their 'thingness', should be a central part of any investigation of their social and cultural significance, the article focuses on the meaning of the mobile phone as a cultural object and commodity sign for various groups of users/consumers. It also concentrates on the social structuring of mobile phone use by young people and addresses the relationship between class and the practices and meanings of mobile phone use in the context of young people's consumption of other media and cultural technologies. It addresses one of the central questions in the sociology of culture-how are consumption tastes and practices related to class-and examines it through the case of mobile phone use. The study suggests that the general 'technosensibility' of young people, which seems a universal generational phenomenon, when interpreted in the context of the consumption of other 'old' and 'new' media and cultural consumption in general, is differentiated according to class and cultural capital. The article concludes that class distinctions produce a digital divide that results in two distinct populations of young users: the interacting and the interacted users.
\end{abstract}

Keywords: mobile phone, young people, cultural capital, class, digital gap, expressive use/pragmatic use, Slovenia

Sociologický časopis/Czech Sociological Review, 2011, Vol. 47, No. 6: 1091-1118

\section{Theoretical framework}

\section{Introduction: the study of cultural technology and social distinctions}

This article explores the social uses of mobile phones as material artefacts and commodities and reveals the links between class and the uses and meanings of the mobile phone as technology and a commodified object. It focuses on the symbolic and on the 'artefactual nature' of the mobile phone and argues that the social analysis of culture should also focus on objects. It also examines how age, economic class, and cultural capital shape the perceptions of the mobile phone

\footnotetext{
* Direct all correspondence to: Breda Luthar and Samo Kropivnik, Faculty of Social Sciences, University of Ljubljana, Kardeljeva pl. 5, 1000 Ljubljana, Slovenia, e-mail: samo. kropivnik@fdv.uni-lj.si, Breda.luthar@fdv.uni-lj.si.
}

C Sociologický ústav AV ČR, v.v.i., Praha 2011 
as a commodified artefact beyond its pragmatic function and how the use of the mobile phone is a socially stratified cultural practice. We focus on young people as the most nonpragmatic or 'expressive' users of the mobile phone and analyse how young people of different social backgrounds and literacy skills use and consume the mobile phone as an object commodified through promotional discourse, which promises not just meaningful sociality but also (pseudo)individuality. In addition, this study suggests that the role of the mobile phone in everyday life should be explained only in the context of the 'lifeworld' into which the mobile phone has been introduced and which it shapes. Douglas and Isherwood [1979] argue that every commodity is linked to other commodities, whose relations as complements and substitutes should be scanned together (in social/cultural research). The incorporation of the mobile phone into the daily life of young people today is achieved through the inclusion of mobile phone culture into the popular culture of teens, for example, through music, concerts, festivals, or blogs that colonise pop culture in order to advertise mobile phones and services. A range of cultural activities revolve around mobile phones, which function as hybrid devices in conjunction with other technologies (text messaging, listening to music, organising daily work routines, parenting, dating, flirting, advertising, the aestheticisation and customisation of the phone itself). Therefore, instead of considering each commodity or cultural practice separately, we should move towards 'considering a particular level of technology that sustains community at a given place and time' [Douglas and Isherwood 1979: 70]. For this reason, the mobile phone and mobile phone consumption need to be understood within the wider context of consumption in general (ICT and 'old' media) and within the framework of cultural and class differentiation and the commodification of everyday life. We would like to suggest that the consumption and incorporation of technology is strongly shaped by a commercial and promotional discourse that creates a mobile phone culture and would like to explore how the incorporation of technology into daily life varies not just by age and gender, but also by class.

This study is a systematic attempt to empirically explore the cultural differentiation of mobile phone consumption and stylisation by young people in terms of class differentiation and in terms of the relationship between the use of mobile technology and the use of other 'old' and 'new' media. It is based on the premise that, along with discursive and political relationships, which have conventionally been the domain of social studies, interaction with objects manifests and constitutes the culture of the society in which an individual lives. Technological tools, such as computers, cars, or mobile phones, are, according to Silverstone and Hirsch, doubly articulated [1992: 21], suggesting that they are not merely physical, material objects (albeit with symbolic meaning), but also a means of maintaining and establishing sociality. ${ }^{1}$ An independent culture of consumption and usage

\footnotetext{
${ }^{1}$ See Williams' notion of mobile privatisation as a way of life and sensibility that is at once mobile and home-centred and was enabled by the motorcar, radio, and later television [(1974) 2003: 19-21].
} 
has developed around the mobile phone, thus extending its social role as a technological tool and a material artefact beyond its utilitarian function or pragmatic functionality. The latter enables coordination in everyday life and permanent availability at work beyond a ritual communicative role. Mobile phones, because of their portability, have become incorporated into the patterns of everyday life and as a central cultural technology should be studied as a consumer object and technology. It is important to note here that the use of mobile technology is associated with a person, not a family or a household. As a consequence, the intensity of promotional activity and branding is not comparable to other media, especially landline telephones, and resembles more the promotional strategy used for MP3 technologies such as the iPod and previously the Walkman.

The research questions addressed in this article are: how do the pragmatic or expressive uses and meanings of the mobile phone vary across social groups, and, in particular, how do economic class and cultural capital shape the uses and meanings of the mobile phone? Is consumption a space in which socially and/or politically marginalised groups-such as young people, and particularly working-class young people - can forge an identity and gain (pseudo)individuality? How are these divisions reflected in the uses and significance of the mobile phone as a consumer object and as an aesthetic object, technological tool, and commodity in the light of class and the cultural capital that shape its use within the complex combination of diverse media? The study pursues two main themes: the use of the mobile phone as a commodified and portable material artefact and its consumption as a symbolic object. The latter is shaped by social and cultural differentiations which constitute the backdrop of mobile phone use and the media mix into which it is incorporated.

\section{Things and cultural objects}

Daniel Miller's Material Culture and Mass Consumption offers a theoretical foundation for the study of contemporary material culture. He argues that the key question for this interdisciplinary field is how everyday objects exist both materially and symbolically. Miller [1987: 85-108; 2005: 5] coined the term the 'humility of objects' to illustrate how objects are socially important precisely because we are not aware of their importance. The less we are aware of them, the more strongly they influence our expectations, create a stage for everyday practices, and shape our normative behaviour. These objects are important because they enable or delimit certain practices and frame life and identity; individuals cannot be considered outside of the material world through which they are constructed, since material goods are directly constitutive of self-understanding and of how we understand others. Humanity does not precede what it creates. Generally speaking, material artefacts can and should be understood as the embodiment of an idea that is realised in the form of a material thing. 
This idea lies at the root of externalisation or objectification (two concepts found in Hegel and Marx), which tries to eliminate the dualism between subject and object. The concept of externalisation underlies the contemporary study of material culture and is important for the analysis of material culture and mass consumption in contemporary capitalism. ${ }^{2}$ Generally, the concept of externalisation suggests that the subject is shaped by creations from the outside world or by the projection of the outside world onto itself through material culture, language, and institutions, such as the nation and religion, resulting in the internalisation (introjection) of these projections. People are constituted through the creation, use, exchange, and consumption of things, and through their (co-)existence with things in the world. The world of things is consequently central to how individual and collective identities are understood. Or, as argued by Woodward [2007: 4], 'by studying culture as something created and lived through objects, we can better understand both social structure and larger systemic dimensions such as inequality and social difference'. Material objects are always cultural artefacts, not just because they represent the lived-in and acted-in environment, but also because they are an integral part of the process of objectification by which social affiliations, everyday practices, identities, and subjectivities are created. In short, commodities produce a certain type of society, and the human world is pervasively artefactual. In his research of new media, Rice [1999: 27] maintains that the exploration of the artefactual nature of new media is crucial for the study of their social role. Goggin [2006: 8] similarly argues that studying the cultural aspects of the mobile phone and the culture of communication makes it possible to study the modernities in which people now live.

As an artefact, however, the mobile phone also encompasses a number of non-material elements. Here, we have in mind the 'proper' use of a mobile phone as an element of self-presentation and performative strategy, the related software, (e.g. wallpaper, ring tone, insider slang used in short messages), and the role of messages in the so-called 'gift economy' of the messaging culture. ${ }^{3}$ The social meaning of an artefact such as the mobile phone includes its surplus value, which transcends the use value of the object. Therefore, it is not only the mobile phone's technofunction (meaning its utilitarian function) that is important, but equally significant is its sociofunction, which involves the manifestation of social relations, and its ideofunction, which involves the symbolisation of more abstract ideas or beliefs [Schiffer 1992: 9-12]. Douglas and Isherwood [1979] use the notion of physical services and marking services. While the mobile phone is

2 There is a certain difference between Hegel's and Marx's understanding of the concept of externalisation; they call it 'Entäusserung' and 'Vergengenstädlichung', respectively (for more on this, see Miller [1987] and Tilley et al. [2006]).

${ }^{3}$ For teenagers, text messaging is a way to communicate news, provide advice and 'therapy', flirt, gossip, and chat. Therefore, the text messaging practice and messages themselves have a symbolic function-to reinforce the community and to shape common narrative history [see also, e.g., Ling 2004: 111]. 
certainly a physical service (it serves to transmit information), it is also a marking service (that is needed for social reasons-for social interaction, integration, and distinction). Katz and Aakhus [2002: 309-310] similarly argue that users oscillate between explicit, manifest reasons and implicit, latent reasons for their phone use: the former relate to form, function, and price, and the latter to the perception of how the mobile phone supports one's conception of oneself and how one is perceived by others. The former set of reasons would refer to what we call a pragmatic use (technofunction) and the latter set of reasons to symbolic use (or sociofunction). More recently Haddon [2003] has made a similar distinction between the use and consumption of mobile phones. Although he does not explain this difference explicitly, we assume that he is referring to the physical use of the product with regard to its pragmatic or utilitarian function, while consumption is a wider concept which also encompasses the expressive use of the mobile phone and its 'thingness'; that is to say, the role of the phone as a cultural artefact (its ideofunction and its sociofunction, in Schiffer's words). Here consuming implies not just using or using up something, but also the pleasure of having an artefact, of gathering information on the product, browsing and touching. In short, it involves the artefact as a meaningful thing, whose meaning is established, appropriated, negotiated, or subverted at different stages of its existence (production, promotion, consumption). We maintain that consumption is intrinsically a cultural practice and that social differences and cultural distinctions are mediated by artefacts. This means that social structures are largely defined by the material culture they involve. Or, as Preston argues [2000: 42], 'the proper functions of items of material culture mediate the government of the actions of individuals by others, and thus mediate the establishment, consolidation and preservation of the power relations which constitute the social system'.

\section{The symbolic and artefactual nature of the mobile phone}

In what way are a technology and the technological object that embodies it, such as a mobile phone, social and cultural? Material objects are socially and culturally significant in at least two different ways. First, there is their symbolic significance, and second, their significance for the organisation of our senses. To study the symbolic aspects of material objects, that is, the meaning of the mobile phone as a cultural artefact, we can draw on the sociology of culture and its analysis of social patterns of consumption, a tradition of analysis best represented by Bourdieu [(1979) 2000]. Or, alternatively, we can refer to the field of cultural studies and investigations into the symbolic meaning of artefacts used, mainly, by subcultures to subvert conventional dress standards, perform and express personal or social identities, and symbolise belonging or create distinctions through a collage aesthetic. ${ }^{4}$ Con4 The most prominent analysis in this field is the ethnographic analysis of subcultures
[see, e.g., Hall and Jefferson (1975) 2006; Willis 1978; Hebdige (1979) 2000]. 
sumption, at least within the study of subcultures, is understood less as a socially stratified cultural practice and more as an active process of adopting commercial objects, as the exploitation of the polysemic nature of mass products to construct oppositional identities, and as political resistance against a hegemonic culture. However, both approaches, the study of symbolic creativity in the canonical texts on subcultures or the study of the hierarchy of taste and the distribution of symbolic resources as part of social distinctions [ibid.], are limited to an analysis of the symbolic properties of the objects, their textuality, not their 'thingness'. That is to say, both are primarily concerned with the symbolic meanings of objects or practices that are understood as sites of cultural and political power within systems of relations with other objects or practices.

In contrast to the structural textual analysis typically used in classical cultural studies or of the Bourdieusian sociology of taste, the sociology of materiality understands artefacts not merely as physical objects/texts with symbolic meanings derived from a semiotic relationship to other objects, but also as media for maintaining and establishing sociality. Material culture is not simply a semiotic representation of social relations or a magical resolution to structural social problems; what is important is the object nature of things and the intertwining of the social and material worlds along with the symbolism of material things. Consequently, the study of the artefactual role of an object, such as a mobile phone, includes not only the symbolic role of hardware or software, but also the social role of materiality and the manner in which technological artefacts shape human practice, for example, by affecting communicative patterns and the construction of the lifeworld, in general. Objects such as the mobile phone may consequently be understood as elements in the creation of 'frames' of action. ${ }^{5}$ Castells et al. [2007: 141-142] introduce the notions of 'technosociality' and 'technosocial sensibility' to emphasise the role of contemporary technologies not just as tools but also as environmental conditions that change the perception of time and space and transform the cultural imagination. The key ways in which new media work as environments consist in the 'different ways in which they involve our senses and shape the relationship between them' [Bennett 2005: 52].

\section{The analytical framework}

\section{The operationalisation of key indicators}

In conformity with the theoretical framework, our empirical research design concentrates on three sets of variables that measure different aspects of mobile phone use on a standard five-point scale: pragmatic use or symbolic use of a mobile

\footnotetext{
5 According to Goffman [(1974) 1986], most of our behaviour conforms to expectations shaped by the frameworks or interpretative schemes that are established in the context of action. See also L. Fortunati [2003] on the humanisation of objects and the relationship between the human body and technology.
} 
phone (thirteen indicators); media environment and integration of the mobile phone as a personal object and the extension of the body into daily life (eight indicators); and finally, attitudes towards regulating the use of mobile technology in public (nine indicators). While the first set of variables is concerned with the textual or symbolic aspect of mobile phone use for its users (or its sociofunction) as opposed to pragmatical aspects (or technofunction), the indicators included in the second set of variables examine the mobile phone's artefactual role and the role of the mobile phone as an object that frames the user's action as an environmental condition. ${ }^{6}$ The aestheticisation of the mobile phone through design and promotion shapes specific patterns of consumption for some users/consumers. Design (the look and 'feel' of a product) and marketing encode the product with identity and meanings (e.g. coolness, sociability, mobility, independence). The expressive use of the mobile phone may be based either on its aestheticisation as an artefact or on its construction as a technological gadget. Both strategies are aspects of its commodification. In both cases, the meaning of the mobile phone for its users extends beyond its instrumental value. However, the distribution of aesthetic and technological knowledge is uneven. One aspect of the symbolic distinction brought about through the use of a mobile phone is the gendered quality of the telephone as a technological artefact: with changes in the labour market, technological skills have become the main domain of hegemonic masculinity, the way physical strength was in the past.

This study therefore conceptualises the use of the mobile phone either as predominantly instrumental, pragmatic, and utilitarian, or as symbolic and expressive. According to Schiffer's [ibid.] categorisation of functions, pragmatic use refers to the mobile phone's technofunction, while the symbolic use includes both its sociofunction and ideofunction, that is, its role as a marking service. The instrumental use is assessed by statements such as, 'for me, it is important that a mobile phone is as practical and as easy to use as possible', and the expressive use by statements such as, 'for me, it is important that a mobile phone looks attractive'. The use of the mobile phone as an aesthetic (or, more narrowly, fashionable) wearable personal accessory, and the fetishising of the mobile phone as an advanced technological artefact and status symbol, are measured by statements such as, 'I frequently replace my old mobile phone so that I do never lag behind'. ${ }^{7}$ The second set of variables is concerned with the mobile phone as a portable and wearable personal object that people carry around with them constantly, and its incorporation into the user's everyday life and into the media mix of mobile phone uses. This includes questions about the intensity of use, the perceived indispensability of the telephone, its use as a terminal for other ICT activities, and its relationship to the use of computers and the Internet. ${ }^{8}$

\footnotetext{
${ }^{6}$ Because of the limitations of survey methodology for measuring the artefactual role of the mobile phone this set of variables should be understood as a proxy for the respondent's 'technosocial sensibility' [Castells et al. 2007].

7 See the Appendix, indicator numbers 1 to 13.

${ }^{8}$ See the Appendix, indicator numbers 14 to 21.
} 
The third set of variables assess perceptions of the use of the mobile phone in public, the private colonisation of public spaces, and views on formal and informal regulation of mobile phone use. We were interested in what respondents thought of 'forced eavesdropping' and the 'balkanisation' of public spaces [Ling 2004: 140], and how much they favour regulating the use of mobile phones in public and imposing an etiquette on users. We used statements such as, 'I don't understand people who coordinate everyday shopping activities over the mobile phone' or 'I find it annoying when people talk on the mobile phone about personal issues in the presence of others', to assess the degree of discomfort about the public presence of mobile phone conversations and to indicate weather the speaker has a lower level of 'technosensibility' and less naturalisation of the mobile phone as an extension of the body. ${ }^{9}$

\section{The operationalisation of sociodemographic and contextual indicators}

An important objective of this study is the empirical operationalisation of social class and the relationship of class and culture. The concept of class denotes the structural social inequality that is manifest in access to economic and other resources (i.e. economic capital, formal and informal education and qualifications, networks of acquaintances and contacts, or social prestige), suggesting that difference in income points to class differences only in very specific social circumstances. Eder [1993: 88-89], for example, states that the vertical classification in advanced modern societies tends to become dependent upon the logic of "having culture"'. The measure of this vertical classification is the quantity of competence. Consequently, the conceptualisation of an objective class position today is much more complex and increasingly constructed on the basis of cultural capital, a term borrowed from Pierre Bourdieu, who operationalises cultural capital as formal and informal education. It is embodied in education and taste, objectified in knowledge and cultural goods, such as books and art objects, and institutionalised in formal qualifications. In general, therefore, the importance of culture in the process of social structuring is growing due to economic changes and the hyperinflation of symbols in consumer capitalism [Crompton 1998: 155].

Our study draws on Bourdieu's operationalisation of class ${ }^{10}$ and on Skog's [2002] categorisation of parent's occupation in his analysis of the role of the mobile phone in teen identity. The study also rests on previous research concerning class structure in Slovenia [Tivadar and Luthar 2005]. Along with family income, several indicators were used to measure the 'objective' class position of young

\footnotetext{
9 See the Appendix, indicator numbers 22 to 30.

${ }_{10}$ Bourdieu argues that official differences produced by academic classifications tend to produce or reinforce real differences by inducing in the classified individuals a collectively recognised belief in the differences and thus producing behaviours that are intended to bring real being into line with official being [(1979) 2000: 25].
} 
respondents, based on the assumption and empirical evidence available that educational differences are constitutive of class positions and that education is increasingly important for life opportunities (for theoretical insights and empirical evidence on this, see Crompton [1998: 216]). The first indicator of a respondent's class is social background, measured by the parent's occupation and resulting in three distinctive classes: service class (work requiring higher education, e.g. physician, university professor, bank manager, lawyer, or museum curator), middle class (technician, primary school teacher, or secretary), and working class (manual factory worker, farmer, driver). The second indicator emerges from attendance at a certain type of secondary school (vocational school, secondary technical school, or grammar school); the third group of indicators is related to a respondent's educational plans and academic self-esteem and aspirations (a desire to complete the education needed to obtain an advanced degree). The fourth group of indicators of 'objective' class position measures the integration of a respondent into an educational culture and his or her attitudes towards formal education. ${ }^{11}$

Additional groups of indicators were employed to grasp the mobile phone users' age, gender, level of education, employment status, geography, religion, foreign language proficiency, musical taste, media consumption (TV, print media and the Internet; frequency and content of consumption), values (mainly attitudes towards ethnic minorities and gender roles), political attitudes (favourite party and politician), notion of the 'good life', use of other 'old' and 'new' media, characteristics of the mobile phones they own (model, technical proficiency, etc.), SMS usage and other contextual characteristics-in total more than one hundred indicators. $^{12}$

After identifying five ideal-type groups of users, we focused on two groups of young users of mobile phones, their social values, cultural tastes, and practices as a potential indicator of class distinctions. The assumption was that various forms of social differentiation, such as class, gender, and age group, are realised and produced through cultural differentiation. We were particularly interested in the sociofunction of mobile phones, assuming that mobile phones are a commodity which is produced and promoted as a representation or sign. The mobile phone as a commodity is mediated through design and lifestyled through advertising and other promotional media discourses or shop designs and displays. This study will below examine how the right to be different is pursued through the choice and significance of a mobile phone, and how consumers search for an identity with the aid of commercial culture, which represents a domain of pleasure and identification.

\footnotetext{
11 The latter was measured by statements such as 'formal education cannot help me much given my plans'.

${ }_{12}$ The questionnaire can be accessed on the project's website (consulted October 2011): http://uploadi.www.ris.org/editor/1134372340ikt2005_mobilna-telefonija_final.pdf.
} 


\section{Data collection}

This article draws on a nationally representative field survey of the uses of information-communication technologies in Slovenian households in 2005..$^{3}$ Standardised face-to-face interviews were conducted at respondents' homes to obtain answers to more than 1000 structured survey questions. The random sample contains 1318 respondents who participated in the survey, which is representative of Slovenia's resident population between the ages of 10 and 74 . The questionnaire was divided into several autonomous parts, which were randomly assigned to respondents. Consequently, not all of the respondents answered all the questions used in our analysis, but the number of collected answers invariably approaches one half of the total sample.

\section{Empirical outcomes-the case of Slovenia}

\section{Key indicators, age, and gender}

As expected, the empirical division of variables according to latent dimensions (i.e. factors; see Johnson and Wichern [1992: 356-458]) fully corresponds to the three-part division of indicators. ${ }^{14}$ The dimension of symbolic versus pragmatic uses of the mobile phone explains most of the differences among respondents and more than the other two dimensions combined (which are effectively of equal importance).

When the sample is broken down according to age and gender we find that every aspect of the expressive use of mobile phones declines with age: ${ }^{15}$ the older the respondents, the more pragmatic and less frivolous are their attitudes towards mobile phones. At the same time, more instrumental use also means less incorpo-

\footnotetext{
${ }^{13}$ The survey RIS-IKT 2005 was conducted at the University of Ljubljana, Faculty of Social Sciences. A detailed description of data collection can be obtained from the project's documentation at (consulted October 2011): http://uploadi.www.ris.org/editor/1134372340ikt2005_mobilna-telefonija_final.pdf.

${ }^{14}$ Using exploratory factor analysis (principal axis factoring and oblique rotation) we calculated factor loadings for three factors with eigenvalues $4.9,2.7$, and 2.4. The fourth factor would have the eigenvalue 1.6, representing such a large fall in value that its inclusion in the model would not explain anything relevant. The first set of thirteen variables can be clearly associated with the first factor, the second set of eight variables with the second factor, and the third set of nine variables with the last factor. The criterion of distinctively highest loading was used and none of the variables was associated with more than one factor. Since oblique rotation was used the third factor can be recognised as related to the first one (factor correlation coefficient -0.3). Factor loadings are reported in Appendix, in columns F1, F2, and F3.

${ }_{15}$ Each variable from the first set of thirteen variables is linearly correlated with age; see the 'Age' column in the Appendix. The letter $r$ stands for the Pearson correlation coefficients [Blalock 1960: 273-301].
} 
ration of the mobile phone as a wearable personal object into a person's everyday life. Differences in the meaning of mobile phones in everyday life and in aspects of how the phone is used can also be identified along generational lines. ${ }^{16}$ While Japanese [see Katz and Sugiyama 2006] and Norwegian [Ling and Yttri 2002] researchers found that the role of the mobile phone as a fetishised object is important for young people, its functionality then being of secondary importance, Finnish researchers found that for young people in Finland the mobile phone is increasingly becoming an 'organic part of everyday life' rather than being an indicator of social status or an object of aesthetic or technological fetishisation [Oksman and Turtiainen 2004: 324]. The difference of just a few years between the Norwegian research (2002) and the Finnish one (2004) was associated with a different level of acceptance of technology in those two countries. The functions and meaning of artefacts are dynamic and things are constantly losing some or acquiring others. The public meaning of the mobile phone is inevitably transformed when its use is widespread and the majority of the population has adopted the new technology. At that point, anyone who wants a mobile phone already has one, the product loses its novelty, and the meaning of the mobile phone is redefined through the banality and normality of its use. Consequently, the relationship with a mobile phone becomes less expressive as it begins to qualify as a standard piece of equipment and an inherent part of everyday life, indispensable for work-related communication and for the coordination of personal life. However, age is not only the most important determinant of the symbolic meaning of the mobile phone. It also determines attitudes towards the use of a mobile phone in public and views about the 'balkanisation' of the public space and 'forced eavesdropping' [Ling 2004: 140]. The demand to regulate the use of the mobile phone in public, that is, to establish a cultural hegemony, slightly increases with age. ${ }^{17}$

Generational differences can only be partially explained by advertising and promotion, that is, by the making the telephone a lifestyle component and implying with it promises of (pseudo)individualisation, a strategy employed in advertising and marketing and targeted at young people. Commercially produced, aestheticised, and promoted objects such as a mobile phone are to a certain degree polysemic. They can possess a variety of meanings and can, within limits, can be interpreted flexibly by their users. The differences in the consumption of mobile phones are, to a certain degree, the result of the communication made possible by the mobile phone as a technological artefact with a distinctive culture: it domesticates the public sphere, enables liberation and permanent control at the same time, frees children from parental control, facilitates membership in a social network, and disturbs the sanctity of a place. In our research, age was found to be the central differentiating factor, which is consistent with available

\footnotetext{
${ }^{16}$ Most of the variables from the second set are correlated with age; see the 'Age' column in the Appendix.

${ }_{17}$ All variables from the last set except one are linearly correlated with age; see the 'Age' column in the Appendix.
} 
results from earlier research on the use of mobile phones among young people in various national contexts [see, ,e.g., Drotner 2000; Ling and Yttri 2002; Skog 2002; Katz and Sugiyama 2006]. For a considerable number of young users, style and design, the decorative aspects of a mobile phone, and the possibility of personalisation through the customisation of the object are constituent elements of a mobile phone's use value. Aestheticisation refers to the appearance or design of the commodity and is achieved through the semiotic work of marketing (advertising, promotion, events marketing, and sponsorship of popular cultural events).

In general, design and aesthetics are more important for female respondents. ${ }^{18}$ The reason for this may be the instrumental role played by fashion and aestheticisation in the process of socialisation into gender roles. Since the mobile phone may be treated as a body part or its extension, its aesthetics play a role in 'women's production of themselves as an image in the process of masquerade' [Lury 1996: 152], that is, in the self-stylisation, creation, and maintenance of a particular look as a defining feature of female subjectivity. Furthermore, the aestheticisation of a technology, such as a mobile phone, may enhance the formation of a relationship with the object. However, taking into account all the indicators of the nonpragmatic uses of the mobile phone, including its technological fetishisation and its sociable and prosthetic roles, the use of a mobile phone as a marking service appears to be more typical for male respondents.

\section{Contexualised patterns of mobile phone use and meaning}

To extract the essence from complex data and obtain a more nuanced picture, the respondents were clustered into schematic types according to three dimensions (three sets of indicators): pragmatic versus expressive use, the intensity of attachment to the mobile phone as an artefact and a tool, and attitudes towards the regulation of mobile phone use indicating that the mobile phone and mobile communication has become a natural presence in the user's life. Since it is impossible to categorise almost 500 respondents according to 30 properties without using formal analytical methods, this study employs a number of clustering methods [Johnson and Wichern 1992: 573-601]. As a result, five schematic types of mobile phone users emerge.${ }^{19}$ Finally, key properties of each group were

\footnotetext{
${ }^{18}$ Independent sample t-tests were used to compare the mean values of the subsamples of men and women for each indicator [see Blalock 1960: 170-176]. Mean differences between the values of key indicators for males and females are reported in the 'Gender' column in the Appendix.

19 Nonstandardised variables were used in all the steps of the analysis. First, a hierarchical clustering based on the Ward method and Euclidian distance as a measure of dissimilarity between units was employed to review the whole process of clustering and to recognise the optimal number of types. The results, i.e. clustering into five distinctive and homogeneous groups, were then optimised by the k-means clustering approach to obtain the final solution.
} 


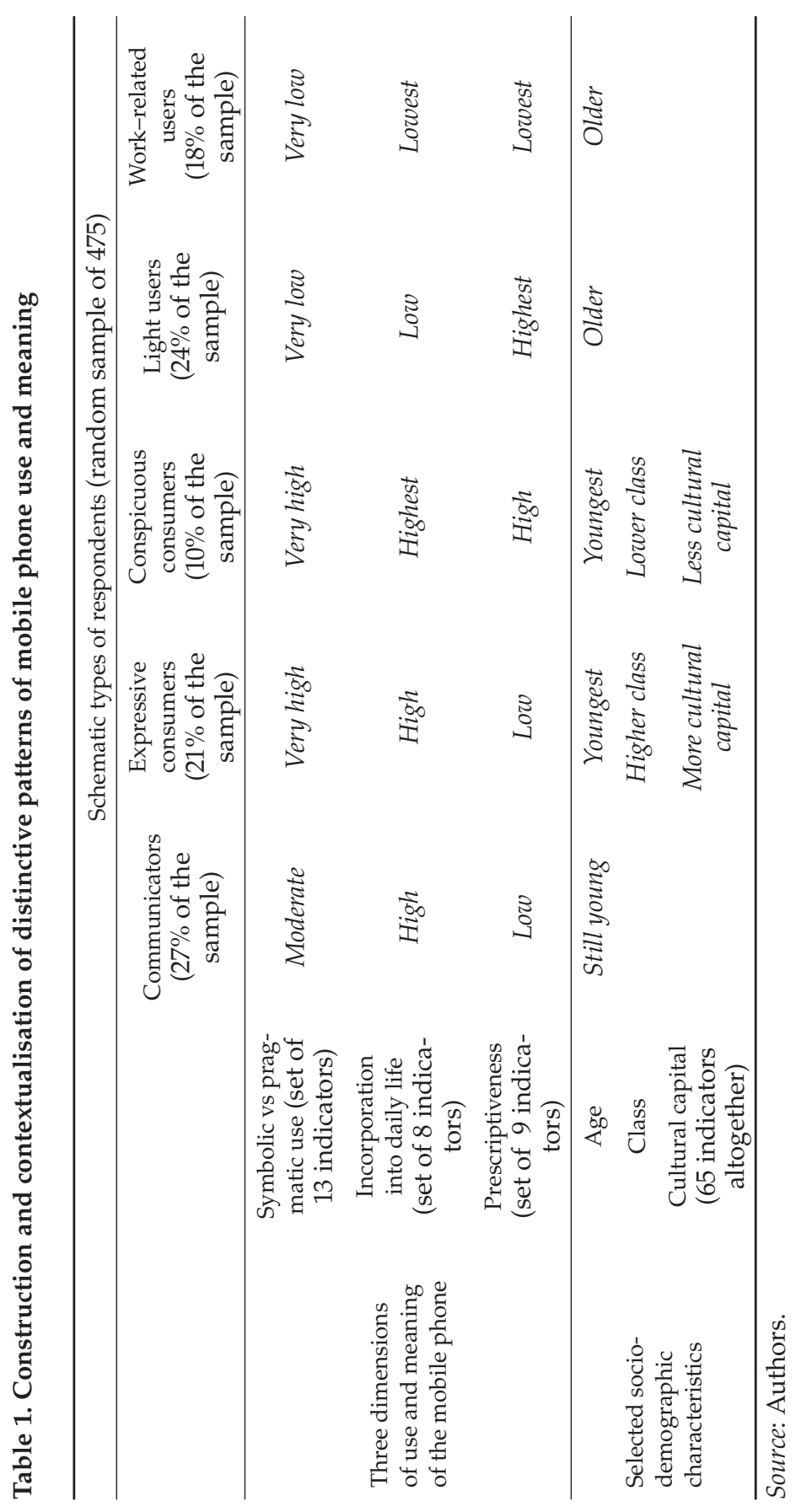


identified according to the group's mean deviation from the sample mean for each of the thirty indicators. The size of the deviation was taken into account, as larger deviations were considered to be more significant. All deviations below 0.25 - which in our opinion is the minimum difference still relevant on a scale from 1 to 5 -were ignored. The group means are presented in the Appendix in the columns Type 1 to Type 5, and they are discussed in the next paragraph.

However, the meaning of the mobile phone and the style of its consumption cannot be isolated from how the mobile phone is incorporated into existing media consumption, cultural practices, and the consumption of ICT in different class, age, and gender cultures. Consequently, in order to avoid using an isolated media-centric approach and to obtain a meaningful explanation for the five clusters of users, five distinctive uses of the mobile phone were contextualised by applying almost 100 additional characteristics representing respondents' lifeworld and social background (from standard sociodemographic characteristics, to musical taste, media consumption, values and political attitudes). ${ }^{20}$ Table 1 presents the merged outcomes of this rather complex and lengthy analysis, a description of clusters according to key indicators (the three dimensions of mobile phone use and meaning), and a contextualisation of clusters according to an extensive list of additional variables, and a more detailed discussions follows in the subsequent chapters.

The results in general suggest that the use of mobile phones is significantly more influenced by age than by class. There is a big age difference between the expressives or 'bricoleurs' and the three groups made up of older users ('communicators', 'older light users', and 'work-related users'). Only for the two very young clusters is the mobile phone an object of aestheticisation, technological fetishisation, and part of a self-presentation strategy, while in the older groups users are much more pragmatic and use the mobile phone either for work or for the 'micro-coordination' of everyday life and 'softening of schedules' [see Ling and Yttri 2002], remote parenting, or simply to maintain key interpersonal relationships across spatial distances; in short, to be part of a society. In addition to this general typisation, there are more detailed findings which will be discussed in the next two chapters.

\section{Older users: pragmatism and gender differences}

Let us first look briefly at the characteristics of the three older and more pragmatic groups of users before turning to the young expressive users. The largest group identified ( $27 \%$ of all respondents) is called 'communicators' and is predominantly female, with high educational aspirations, and around the age of 20; most young

\footnotetext{
${ }^{20}$ Associations between clusters and these additional characteristics are analysed by comparing raw percentages in contingency tables or by comparing groups' means and reported in the subsequent interpretations.
} 
female adults belong to this group. Communicators emphasise the importance of a mobile phone's performance and that it be easy to operate. The mobile phone does have a symbolic role for them; its key role is to maintain social networks and framing communicative patterns, or as a means of coordination and social support. For communicators the telephone is indispensable, and they can hardly imagine everyday life without it. If forced to limit their budget, communicators would give priority to the mobile phone over the Internet, travel, or buying new clothes. The important communicative role of the mobile phone and its incorporation into the daily life of members of this group is evident in their tolerance towards the intrusion of the mobile phone into the public sphere and their very non-prescriptive attitude towards any suggestions of regulation. Their intensive use of the computer for work- or school-related tasks and their attitude towards the mobile phone as a tool of communication rather than as a personalised, aestheticised gadget are areas where their mobile phone use resembles that of older users.

The second-largest group, comprising $24 \%$ of the respondents, is considerably older than the average user and is mainly female. For these 'older light users' simple use is far more important than the technological features, label, or design of the mobile phone. These respondents strongly support various forms of regulating mobile phone use and are concerned about mobile phone etiquette in public, which may be an indicator of their being more prescriptive in general and not just in relation to mobile phone use. Since they often do not carry a mobile phone with them, they do not exploit the main feature of the mobile phone, that is, its portability. Also, their patterns of sociality remain barely changed by new mobile phone technology.

The third group of pragmatic users, 'work-related users' (18\% of all respondents), are heavy mobile phone users, predominantly in relation to work, and, in their own opinion, their use of their mobile phone is strictly instrumental . They are more message-senders than they are socialisers and network maintainers and are less interested in the aesthetic attributes of mobile phones. The majority of these respondents are male, have a university degree, and live in a city. Their mobile phone bills are paid by their employer, so they associate the telephone with time-thickness, being constantly available, and the blurring of boundaries between work and the private sphere. The intensity of mobile phone use is high, and because the mobile phone is not an intimate machine but a tool for transmission and a means of employee management, they consider it as a non-essential tool that they could easily do without.

In many respects (education, residential area, lack of interest in stylistic features, frequency of use) this group resembles the communicators. But while communicators (female group) find the telephone indispensable for managing social networks and 'social administration' [Ling 2000: 63], the predominantly male group of work-related users mainly use it for specific arrangements and for instrumental coordination. The interpretation and use of the mobile phone obviously is gendered, and different evaluations of the mobile phone are a marker of gender differences or of the discursive legitimation of gender differences. The 
mobile phone is interpreted by male respondents as part of a utilitarian frame of reference equated with the rational transmission of information and assimilated into a work frame. The division of rational talk as work on one hand and talk as communication on the other is part of the symbolic, ideological gap between rational production and irrational consumption and part of the gender division of labour and emotion. The sociable use of a mobile phone and talking for the sake of communicating as part of the maintenance of networks, community building, and caring for others is feminine, while sending and receiving messages and transmitting information is part of paid work, rational, and masculine. The cultural differences between the groups emanate from gender differences, not vice versa. Media consumption of the two groups also shows to what extent cultural practices and tastes are gender-specific and how a specific type of mobile phone use should be interpreted as part of a larger media mix. While work-related users read quality and local daily newspapers (information-seeking), communicators are readers of tabloids, women's magazines, and celebrity magazines (communication, community-building).

\section{Young consumers: universal mobile culture and class distinctions}

More central to this investigation, however, are the last two socially and culturally distinct groups, which use and interpret the mobile phone far beyond its instrumental role. Both groups are much younger than the three previous groups of more pragmatic users and represent two distinctive youth cultures. Use of the mobile phone and the sociability created and supported by mobile communication are similar in both groups: both clusters belong to the universal mobile culture and feature 'technosocial sensibility' [Castells et al. 2007: 141]. However, contextualising their consumption and interpretation, we find consequential differences between them. Findings about the first group, 'young expressive consumers from a middle-class background' (21\% of all respondents), and the second one, 'young conspicuous consumers from a working-class background' $(10 \%$ of all respondents) suggest that although middle-class and working-class youth both attach symbolic meaning to the mobile phone and use the mobile phone as a symbolic consumer artefact, certain important differences between these two groups remain concealed. There are considerable differences in cultural capital and, consequently, also in cultural tastes and practices (musical taste, perception of a 'good life', attitudes towards travel and foreign countries, nationalism, sexism, or political attitudes) and some differences in their use of other communication and information technologies.

Young people in both groups are heavy users of mobile telephones. They use the mobile phone as an aesthetic object, a status symbol, and/or a technological fetish. Middle-class teenagers in particular attach importance to the design of the phone and are, at the same time, technophiles attracted to the latest technology in mobile gadgets and their performance. They constantly carry their 
telephone with them as an inextricable part of their daily life. It is not just a tool of communication that enables them to be a part of society, it is also a personal, individual device and a portable aesthetic artefact always attached to the person and closely associated with clothing and fashion.

Both groups combine media in different ways, and any newly acquired medium (such as a mobile phone) is always introduced into a pre-existing environment and gains meaning in part from the already established consumption of media (particularly the Internet and the use of the personal computer; see Livingston [2002:43]). In addition to distinct differences in social and cultural orientations of young expressive users (cultural tastes and practices, social values and attitudes, media consumption), the most important distinction between the two groups of young users lies in the relationship between mobile phone use and the use of other ICT. These differences directly relate to class affiliation as measured by economic and cultural capital, including educational capital. We expected that class position would shape the use of media in general and that we would find differences between both clusters in terms of the relationship between mobile phones and other media, particularly the use of the Internet and computers, but also distinctive cultural tastes and practices.

'Young expressive consumers from a middle-class background' (a balanced number of male and female respondents with an average age of 18) are heavy users of computers. While the telephone is a private medium used to maintain private social networks and becomes a 'communicational node' [Castells et al. 2007: 152], the computer is used for a whole range of different activities beyond playing computer games: for instance, school work, downloading films or music, to participate in chat groups and discussion forums, and generally, the acquisition of cultural capital and participation in the mainstream world of education and work. They exhibit a libertarian or cosmopolitan attitude towards social values and the definition of a good life and are able to transcend national boundaries. In contrast to the average population, the political attitudes of this group are more liberal, a significantly larger number understand and speak English and have a preference for rock, pop, and various types of alternative music, and they do not read daily newspapers. Shopping abroad, traveling in Europe, and visiting friends to them represent 'the good life'.

'Young conspicuous consumers from a working-class background', the smallest group, are predominantly non-urban, in-school, male, and with an average age of 18, and more likely to have the lowest volume of cultural capital. They are the most expressive users of mobile phones, owning the most expensive telephones of all five identified groups of users, but scoring low on ownership of personal computers at home or on home access to the Internet. The key distinction between the middle-class young users and the working-class young users lies in the use of ICT. Generally, ICT is used almost exclusively for computer games and significantly less for school-related tasks, but also less for web surfing, downloading music, chat rooms, and discussion forums. Their 'objective' class position is homologous with their educational capital and cultural preferences and practices: 
fewer of them speak English and a significantly larger share of working-class respondents listen to commercial folk music ('turbo-folk' music), have modest educational aspirations and share a sceptical view of formal education. While for young people from a the middle class background the educational system is a familiar environment, so they can cope with it effectively and feel at home there, working-class consumers typically resort to self-exclusion, either by underestimating themselves, by devaluing the school system, or by giving up in the face of expected failure. ${ }^{21}$ While young middle-class users, who score significantly higher on the intensity of mobile phone use (measured by number of phone calls per week), would choose the Internet over the mobile phone, young working-class users would give priority to the mobile phone over the Internet if forced to choose.

The analysis shows that two class-specific youth subcultures exist that share dispositions, lifestyles, and typical interpretative schemata that shape their cultural practices and their experience of social world. ${ }^{22}$ According to their objective class position (parents' occupation, type of school attended, academic self-image, school attitudes, and academic aspirations), and the amount and type of cultural capital (musical taste, reading culture, foreign languages, social values and attitudes), the mobile phone use of working-class youths corresponds to their cultural practices and discourses: they spend less time using the Internet, particularly for school work, and their use of ICT is generally narrower, more passive, and less engaged. In terms of social values and cultural resources such as knowledge of foreign languages, they are considerably more nationalistic and parochial and less tolerant and cosmopolitan. This is evident in their intolerant attitude towards immigrants and their very limited interest in traveling abroad. Fewer of them speak English, but also fewer of them speak any other foreign language, than the 'young expressive users from a middle-class background', which represents an objective limitation to their openness to culture transcending national boundaries. This is a predominantly male group that exhibits a typical working-class form of masculinity, particularly with respect to their view of school culture, formal education, and gender roles. Specifically with respect to women's rights and attitudes to migration and ethnic minorities, they tended to have traditional perception of femininity and they espouse a nationalistic opposition to ethnic minorities.

\footnotetext{
${ }^{21}$ This is more often true for the young men than the young women in our sample. The attitude of boys to school may have to do with the production of gender identity, where the issues of hegemonic masculinity, the attitude to the formal educational system, and class/cultural capital are closely intertwined. See also Paul Willis's authoritative text on this topic [1978].

${ }^{22}$ Eder [1993] argues that to grasp subcultural differences the social scientist must investigate the interpretative schemata behind cultural preferences that determine the cultural praxis in a given society. Class-specific subcultures are defined by specific schemata of experiencing and interpreting the social world. In the context of our study this means that differences in consumption and stylisation should not be treated as superficial, as they are linked to the distinctive worldview schema of a given group.
} 


\section{Conclusion}

This article examined the symbolic and 'artefactual nature' of the mobile phone, that is, the mobile phone as a technological and consumer artefact, and on the issue of the cultural meaning users attach to the mobile phone as a material consumer object and as an element of self-presentation. In addition, the study focused on young users and explored how class correlates with the meaning and uses of a mobile phone, and how its inclusion in the consumer culture and literacy skills articulates class differences. The survey was designed, in part, to contribute to the study of class differentiation and cultural distinctions connected with mobile phone use among young people in Slovenia.

Not surprisingly, the communicative practices and perceptions typically associated with the mobile phone as a consumer and aesthetic artefact proved to be strongly shaped by age. Older people attach more importance to the practical aspects of the mobile phone, and particularly to the fact that the mobile phone is usable and 'operates smoothly'. Correspondingly, the study yielded two very young groups of consumers, which in general resemble each other by the intensity of their mobile phone use, their patterns of use, and, primarily, by their approach to the mobile phone as an aesthetic and technological consumer object and a portable communicational node. These groups are essentially different from older users, particularly with respect to the importance they attach to the phone as a consumer object, how much they use it, and how they incorporate it into their everyday lives as an extension of their bodies. For teenagers, the mobile phone is an organic part of everyday life [see Oksman and Turtiainen 2004], and for many also an indicator of status, or a fetishised aesthetic object that can be personalised and thereby involved in the process of personal identity construction and in the performance of pseudo-individuality that is promoted by marketing discourse aimed particularly at teenage users. The 'proper' use of the mobile phone in public and personalisation of its features (ring tone, wallpaper, mobile phone cases and pouches) are elements of self-presentation. For teenagers, mobile phone communication is a social stage during which, to borrow from Erving Goffman [(1974) 1986], the mobile phone shapes the codes and conventions of communication and, therefore, frames the communicative situation.

The fundamental argument of this study is the need for a contextualised treatment of mobile communication. The two teenage cultures in this study show that the larger media context of mobile communication is particularly important for meaningful interpretations. Thus, the meaning of mobile phone use can only be established through an analysis of the relationship between mobile phone use and the use of different, pre-existing media (particularly computer communication and internet use). In other words, the use of previous media contextualises, shapes and is transformed by the adoption of new media (mobile phone).

The general 'technosensibility' of young people, which seems, at first glance, a universal generational phenomenon, is, when contextualised by cultural prefer- 
ences, practices and by sociodemographic variables, differentiated according to class/cultural capital. This study suggests that what has come to be known as a 'digital gap' [see also Skog 2002] is in reality the articulation of objective and subjective class positions. Both youth class cultures embrace a technosocial sensibility, enabled by the mobile phone and promoted by the interests of the mobile industry; the two youngest groups in general resemble each other in their use and signification of the mobile phone only on the level of more pragmatic or more expressive use of the mobile phone and in the intensity of the integration of the mobile phone into daily life. In contrast to adult users, the majority of young people do have an expressive attitude towards the mobile phone, regardless of their class location. Their engagement with the mobile phone concerns not only its practical utility, but its aesthetic aspect and its 'thingness', as an object available for aesthetic appropriation and an artefact with an instrumental role in the formation of social hierarchies. However, the nature of its symbolic meaning varies across class fractions. In other words, the nature of 'cool' varies between different youth cultures.

The distinction between two expressive youth mobile cultures can be interpreted with the help of data on media use in general and on the cultural capital that shapes different uses in the background. While working-class teenagers use the mobile phone as their central and most important entertainment medium, for middle-class teenagers it represents a communication medium used alongside computer technology, which occupies the central role for school and work-related tasks. ${ }^{23}$ Working-class teenagers are conspicuous consumers of mobile technology and own the most expensive mobile phones, which are used as tokens of one's status. This group uses mobile technology and the ICT mainly for narrow entertainment purposes and as a result their use is strongly influenced by promotional discourse. Middle-class teenagers, on the other hand, are, to a certain degree and with limitations, able to negotiate the promotional discourse of the mobile phone industry and use ICT and mobile technology as a site of individual achievement, while working-class youth have a limited amount of cultural capital and are marginalised within mainstream education.

Class distinctions produce a digital divide resulting in two distinct populations: the interacting and the interacted users [Castells 1996: 371]. The former have the economic and cultural resources to make use of the medium and to negotiate promotional discourse. The latter, however, are confined to commercially defined and pre-packaged options. The struggle for recognition and social mobility is pursued in the domain of the consumption of the mobile phone as a technological artefact and aesthetic object/commodity. While they feel excluded from the official school culture and competitive work culture in transitional capitalist society, the working-class youth studied in our research experience consumption as a domain of autonomy, as an empowering experience with an important role in the

${ }^{23}$ Livingston [2002: 112] notes how book-lovers and PC fans are more often middle class, while music fans are more often working class. 
reproduction of the myth of unlimited social mobility. For young middle-class users the mobile phone is an aesthetic object, a wearable and portable artefact that encourages aesthetic disposition [Bourdieu (1979) 2000: 28], a playful personalisation of the artefact through bricolage. For working-class teenagers, on the other hand, it is more a status object than an object of aesthetic contemplation and they are influenced much more by the commercially defined meaning of brands and the uses encouraged by the mobile phone industry. Differences in the amount of cultural capital between the two groups are manifested precisely in this distinction. The study of social patterns of consumption should therefore move away from examining consumption objects towards analysing the distinctive practices of different groups of users and interpretive schemata behind those practices.

We demonstrated that patterns of use by young people vary by cultural and economic capital across a variety of dimensions. Most of the research on the symbolic aspects of mobile communication among young people interprets the practices of use primarily as expressions of individual creativity and the appropriation of and negotiation with commercially defined meanings. However, our results show that while technosocial sensibility is a universal aspect of contemporary mobile culture when mobile phone use is set in the context of the use of other 'old' and 'new' media and is interpreted against the backdrop of the class position, social values, and cultural preferences of users, the seemingly general classless technosensibility of young people is clearly differentiated by class.

BREDA LUTHAR is a professor of media and communication studies at the Faculty of Social Sciences, University of Ljubljana, Slovenia. She has a background in sociology and her research focuses on popular media, cultural consumption and class, and contemporary material/consumer culture. Her recent publications include 'Food, Ethics and Aesthetics' (with B. Tivadar, Appetite, 2005), 'Remembering Socialism: On Desire, Consumption and Surveillance' (Journal of Consumer Culture, 2006), and 'People Just Like Us Political Celebrity and Creation of National Normality' (Cultural Studies, 2010).

SAMO KROPIVNIK is an associate professor of social sciences methodology at the University of Ljubljana, where he teaches courses on research design, marketing research, and political science methodology, and participates in research projects with pragmatically designed exploratory and descriptive research approaches in general and the use of multivariate methods such as clustering, factor analysis, and regression.

\section{References}

Bennett, Tony. 2005. 'The Media Sensorium: Cultural Technologies, the Senses and Society.' Pp. 51-96 in Media Audiences, edited by Marie Gillespie. Maidenhead: Open University Press. 
Blalock, Hubert M. Jr. 1960. Social Statistics. London: McGraw Hill.

Bourdieu, Pierre. [1979] 2000. Distinction. London: Routledge.

Bourdieu, Pierre and Jean-Claude Passeron. [1977] 2000. Reproduction in Education, Society and Culture. London: Sage.

Castells, Manuel. 1996. The Rise of the Network Society. Oxford: Blackwell.

Castells, Manuel, Mireia Fernandez-Ardevol, Jack Linchuan Oiu and Araba Sey. 2007. Mobile Communication and Society. Cambridge, MA: MIT Press.

Crompton, Rosemary. 1998. Class and Stratification: An Introduction to Current Debates. Cambridge: Polity Press.

Douglas, Mary and Baron Isherwood. 1979. The World of Goods. Towards an Anthropology of Consumption. New York: Basic Books.

Drotner, Kristen. 2000. 'Difference and Diversity: Trends in Young Danes' Media Uses.' Media, Culture and Society 22 (2): 149-166.

Eder, Klaus. 1993. The New Politics of Class. London: Sage.

Fortunati, Leopoldina. 2003. 'The Human Body: Natural and Artificial Technology.' Pp. 71-90 in Machines That Become Us, edited by James Katz. New Brunswick and London: Transaction Publishers.

Goffman, Erving. [1974] 1986. Frame Analysis. Boston, MA: Northeastern University Press. Goggin, Gerard. 2006. Cell Phone Culture. London: Routledge.

Haddon, Leslie. 2003. 'Domestication and Mobile Telephony.' Pp. 293-310 in Machines That Become Us, edited by James Katz. New Brunswick and London: Transaction Publishers.

Hall, Stuart and Tony Jefferson (eds.). [1975] 2006. Resistance through Rituals: Youth Subculture in Post-War Britain. London: Hutchinson.

Hebdige, Dick. [1979] 2000. Subculture: The Meaning of Style. London: Methuen.

Johnson, A. Richard and Dean W. Wichern. 1992. Applied Multivariate Statistical Analysis. London: Prentice Hall.

Katz, James E. and Mark Aakhus (eds.). 2002. Perpetual Contact. Cambridge: Cambridge University Press.

Katz, James E. and Satomi Sugiyama. 2006. 'Mobile Phones as Fashion Statements: Evidence from Student Surveys in the US and Japan.' New Media and Society 8 (2): 321-337.

Ling, Richard. 2003. 'Fashion and Vulgarity in the Adoption of the Mobile Telephone among Teens in Norway.' Pp. 93-102 in Mediating the Human Body, edited by Leopoldina Fortunati, James E. Katz and Riamonda Riccini. Mahwah and London: Laurence Erlbaum.

Ling, Richard. 2004. The Mobile Connection. Amsterdam: Elsevier.

Ling, Richard and Brigitte Yttri. 2002. 'Hyper-coordination via Mobile Phones in Norway.' Pp. 255-273 in Perpetual Contact, edited by James E. Katz and Mark Aakhus. Cambridge: Cambridge University Press.

Livingston, Sonia. 2002. Young People and New Media. London: Sage.

Miller, Daniel. 1987. Material Culture and Mass Consumption. Oxford: Basil Blackwell.

Oksman, Virpi and Jussi Turtiainen. 2004. 'Mobile Communication as a Social Stage.' New Media and Society 6 (3): 319-339.

Preston, Beth. 2000. 'The Functions of Things: A Philosophical Perspective on Material Culture.' Pp. 22-49 in Matter, Materiality and Modern Culture, edited by Paul M. Graves-Brown. London: Routledge.

Rice, Ronald E. 1999. 'Artifacts and Paradoxes in New Media.' New Media and Society 1 (1): 24-32.

Schiffer, B. Michael. 1992. Technological Perspectives on Behavioral Change. Tucson and London: University of Arizona Press. 
Silverstone, Roger and Eric Hirsch. 1992. Consuming Technologies. London: Routledge. Skog, Berit. 2002. 'Mobiles and the Norwegian Teen: Identity, Gender and Class.' Pp. 255-273 in Perpetual Contact, edited by James E. Katz and Mark Aakhus. Cambridge: Cambridge University Press.

Tilley, Cristophe, Webb Keane, Susanne Kuchler, Michael Rowlands and Patricia Spyer. 2006. Handbook of Material Culture. London: Sage.

Tivadar, Blanka and Breda Luthar. 2005. 'Food, Ethics and Aesthetics.' Appetite 44 (2): 215-233.

Williams, Raymond. [1974] 2003. Television: Technology and Cultural Form. London: Routledge.

Willis, Paul. 1977. Learning to Labour: How Working Class Kids Gets Working Class Jobs. London: Saxon House.

Willis, Paul. 1978. Profane Culture. London: Routledge and Kegan Paul.

Woodward, Ian. 2007. Understanding Material Culture. London: Sage. 


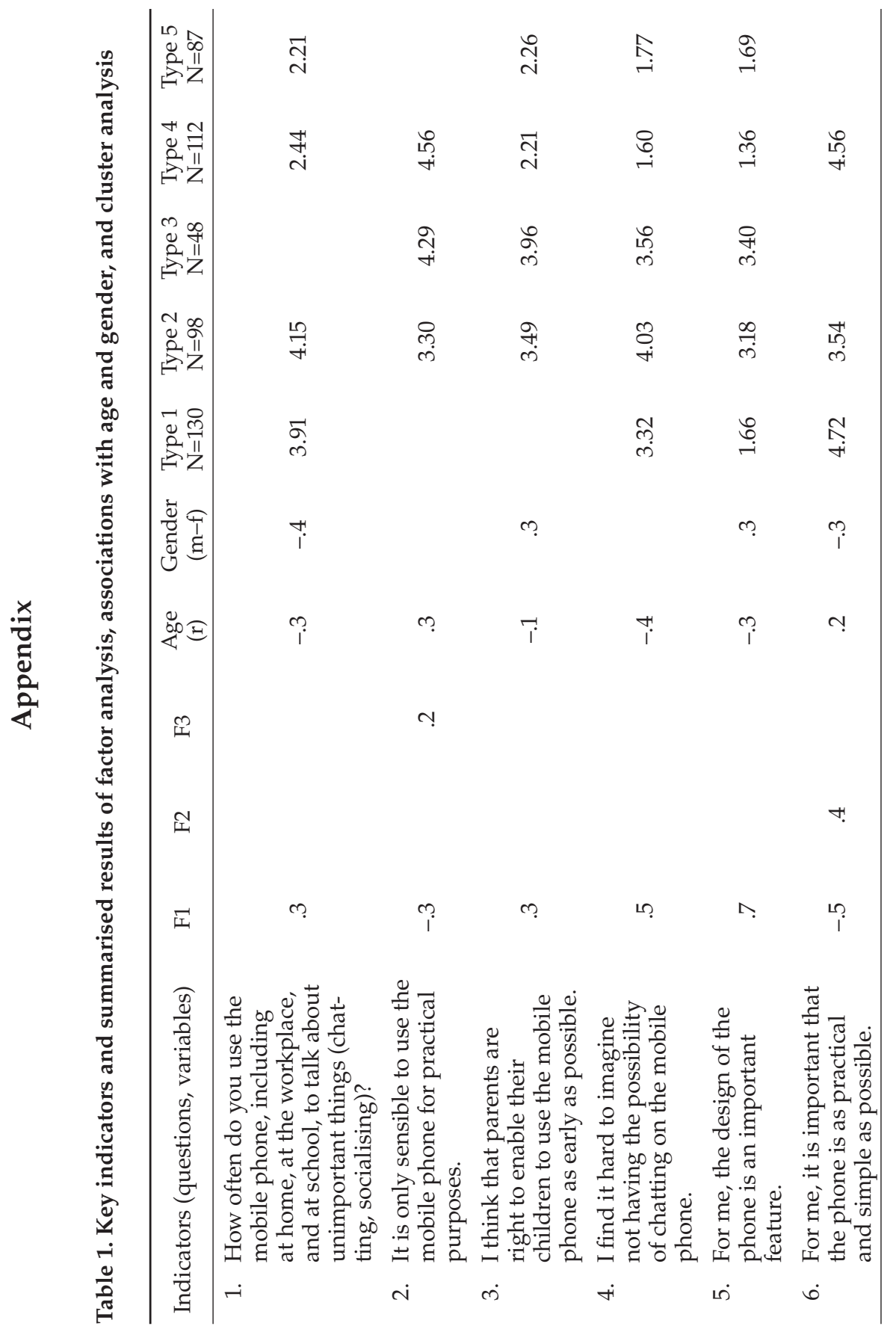




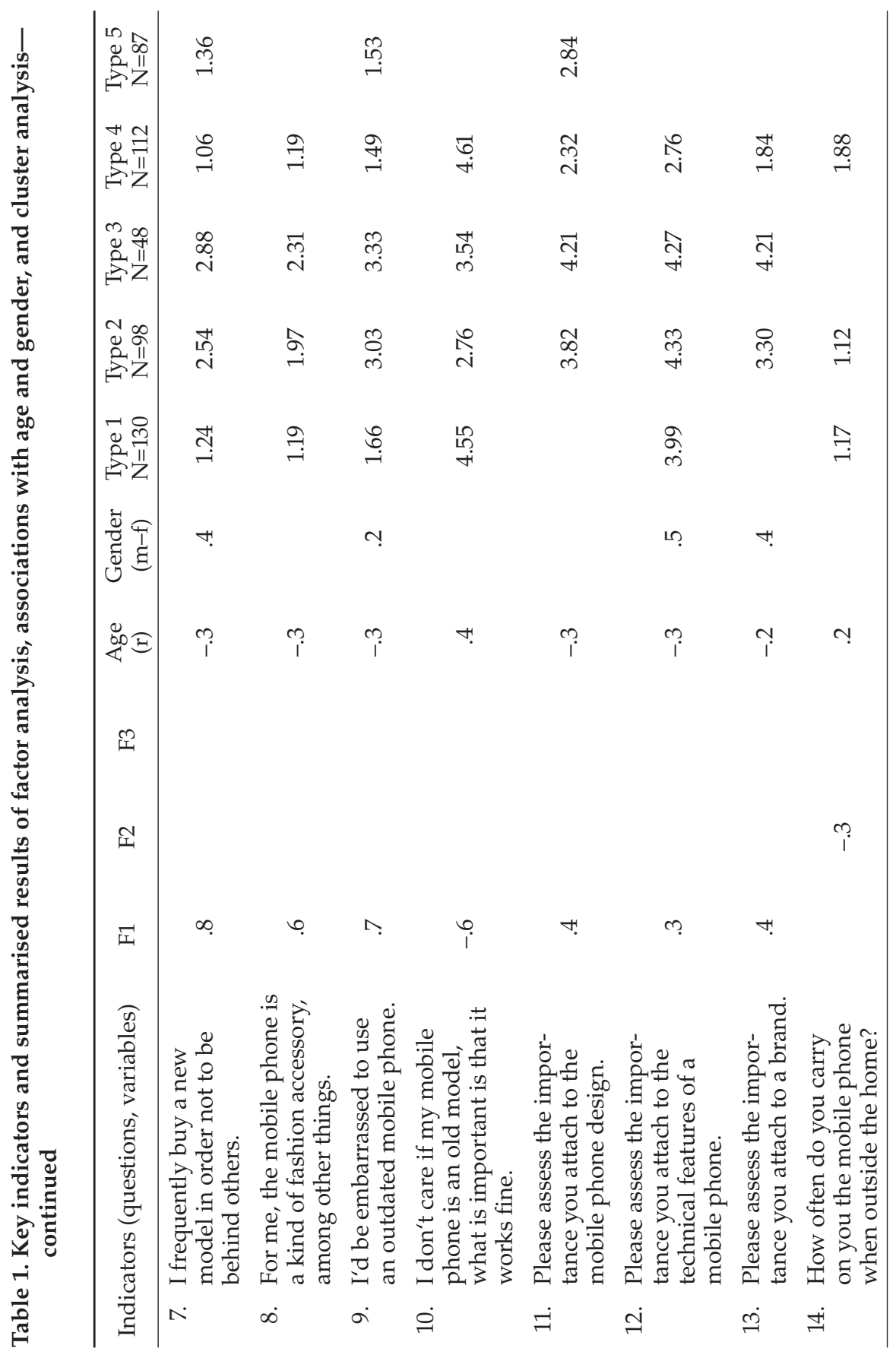




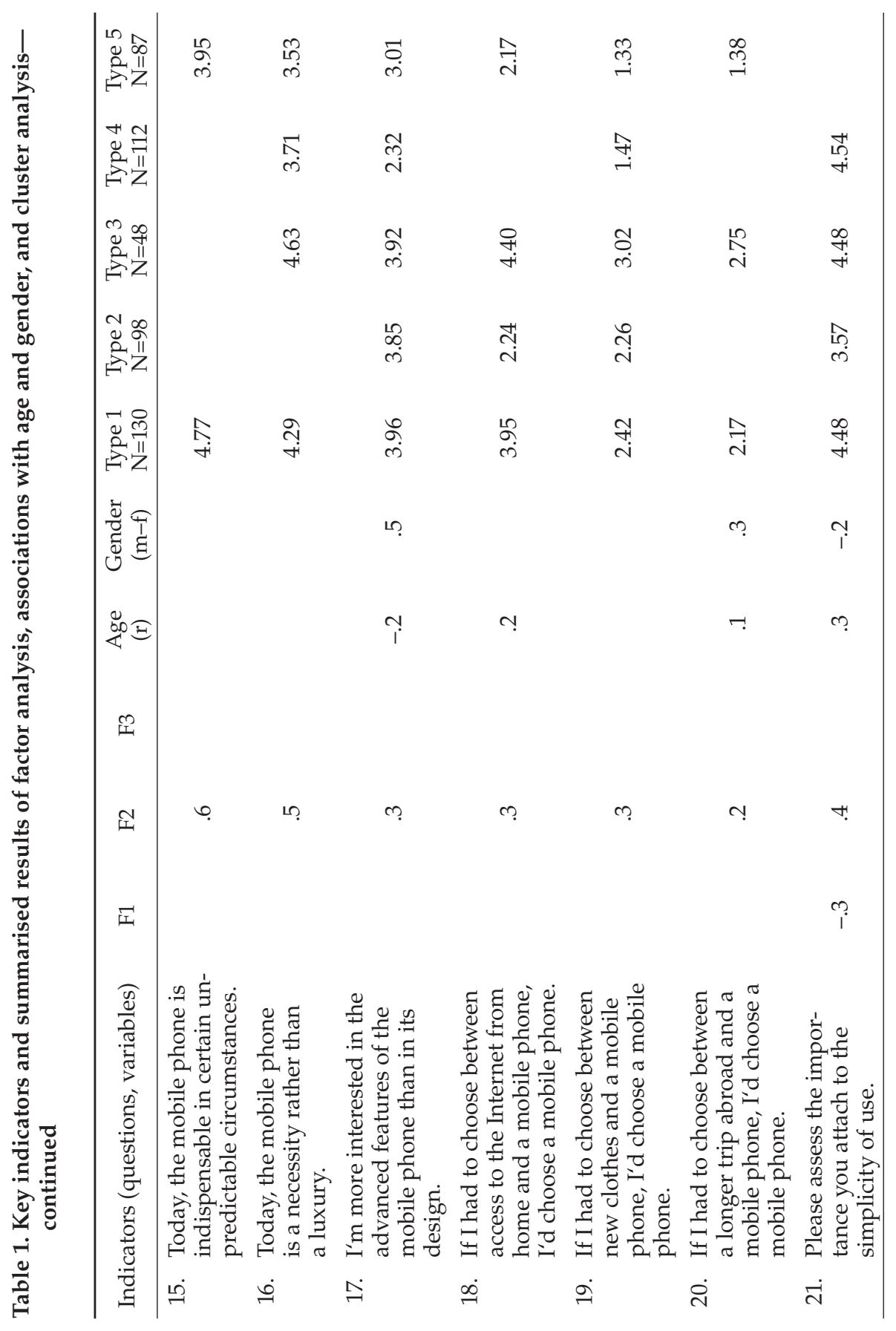




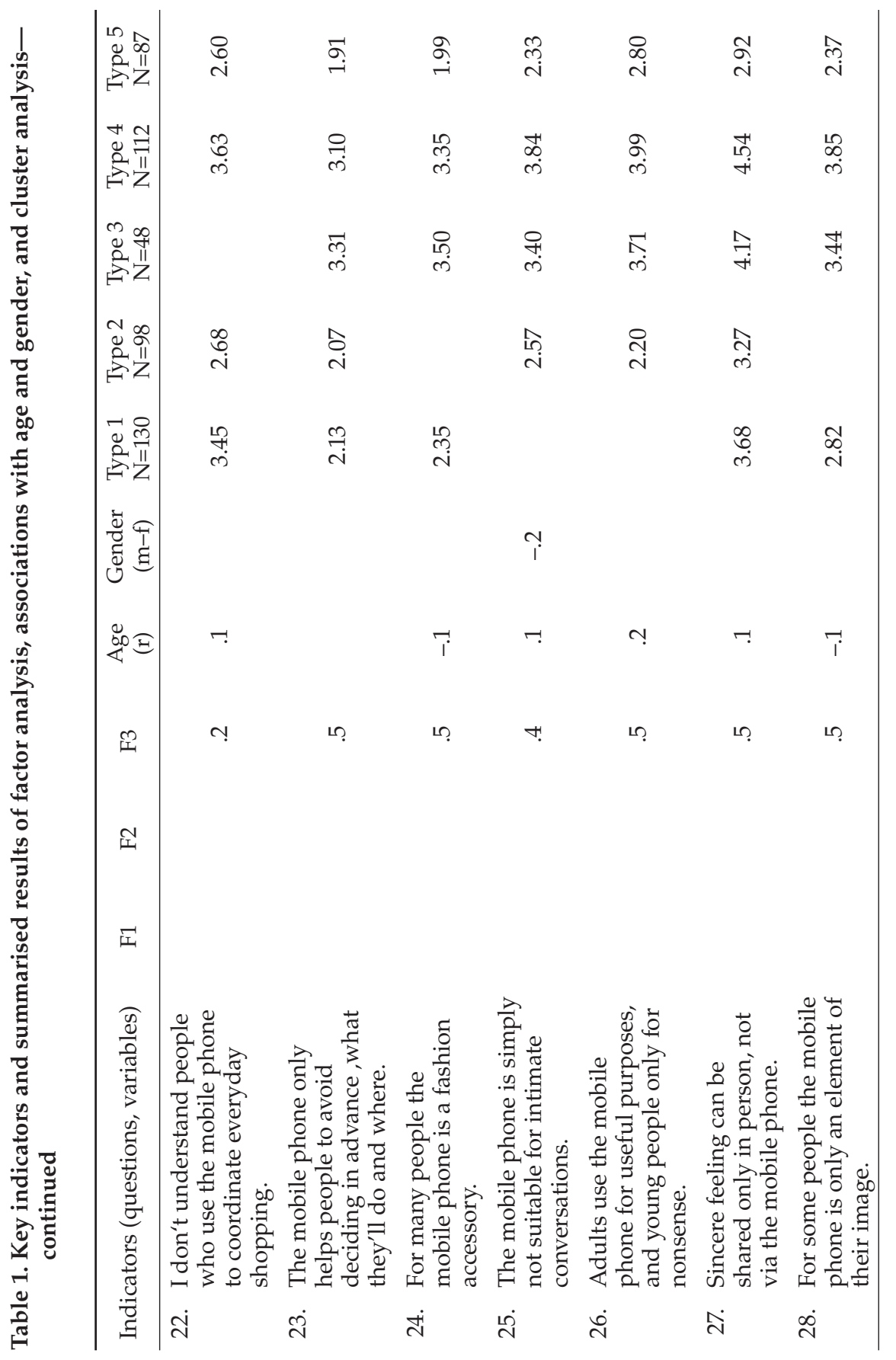




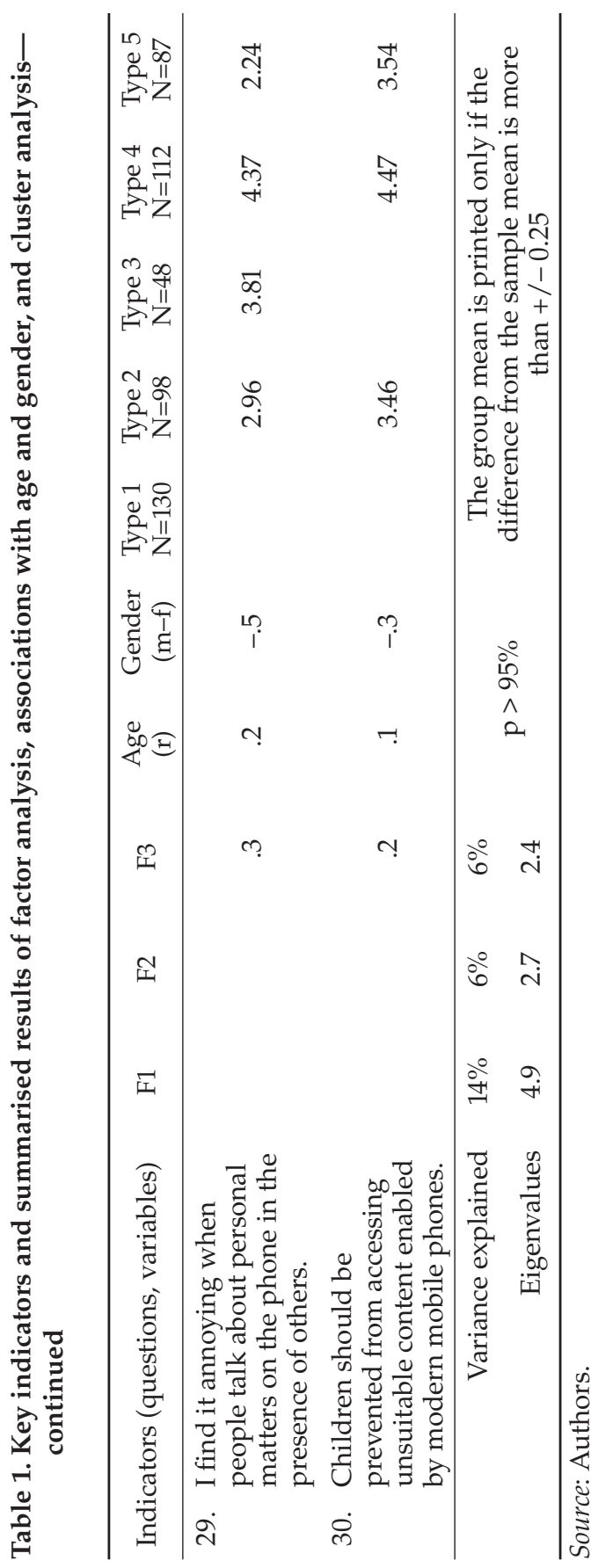

